\title{
Using Cultural Capital in the ESL Classroom: One Teacher's Journey
}

\author{
Dovis Pollock, Department of Spanish and Portuguese, University of Kansas
}

Keywords: Cultural capital, soft skills, metacognitive skills, professional development, MIDTESOL

\begin{abstract}
Bourdieu's concept of cultural capital can help ESL instructors develop professionally and can lead to other related concepts that can address behavioral issues in the classroom and facilitate instruction. To illustrate my professional journey, I begin by focusing on a simple definition of cultural capital and consider how it relates to other areas such as soft skills and metacognitive skills. The educational experiences with respect to cultural capital and other skills that many of our international students have can vastly differ from what is found in American classrooms. This is especially true of students who have been taught in a culture where they memorize facts, do not ask questions or argue their point of view, and have not been involved in any creative process related to learning. Therefore, it is important to explicitly teach these skills. I conclude by sharing some examples of how I addressed and taught cultural capital in the classroom and give ideas of how to create one's own mini-lessons.
\end{abstract}

\section{Introduction}

A couple of years ago when I was having some behavioral problems in my classes, I voiced my frustration to a colleague saying, "In addition to the course material, I need to teach my students how to learn. Sometimes I even need to teach them how to behave in the classroom!” To which she questioned, "You mean, you need to teach them cultural capital?" This was the first time I heard the expression, so I immediately searched for the term and found a simple definition. This started my journey into this complex topic of cultural capital. For my purposes, I just wanted to understand what it was, if my students needed it, if it can be taught, and if so, how could I teach it? As I started reading and learning about cultural capital, I started implementing cultural lessons in my own classrooms with positive results.

\section{What is Cultural Capital?}

A simple definition of cultural capital is that it is a collection of knowledge, skills, education, and mannerisms that people acquire from their family's attitudes, social standing and educational background (Bourdieu, 1991, pg. 14). Cultural capital involves a deeper set of rules and attitudes towards knowledge and this deeper cultural knowledge constitutes part of each student's past learning experience, which is brought into the classroom to the student's advantage or disadvantage.

Using this understanding of cultural capital, I started to think about it as it relates to what students have experienced in their country and in their homes, and how they bring these experiences into the US 
educational context. These attitudes, habits, and skills reflect the culture students come from as well as their family background. Many of our students come from vastly different classroom settings. They might be coming from classrooms where they are one in a class of 30 or 40 students or where they have never engaged with other students and maybe not even with their teacher. Alternatively, they may come from an all-girls or all-boys classroom. Another difference is that they may have never worked in collaborative groups or engaged in problem solving with other students. Therefore, as experienced ESL instructors know, our international students can have very different sets of classroom rules and experiences and even expectations of how they are supposed to behave.

Another difference related to cultural capital is how students learn. They might come from a culture where they memorize facts, where creativity or critical thinking are not as important, and/or where beliefs and norms are vastly different from our Western beliefs and values. Therefore, the cultural capital they are bringing into my classroom is vastly different from the capital I'm using, and expecting to be used in my class, which becomes a problem. We are dealing in different currency. All successful ESL instructors learn to teach in this environment and the concept of cultural capital, in particular, has helped me.

\section{Soft Skills and Metacognitive Skills}

As I continued to consider the profound effects of cultural capital in the classroom, my search led me to other areas such as soft skills and metacognitive skills. Soft skills refers to people skills and are very desirable in the business world today (Cimatti, 2016). Some examples of soft skills I consider important to education would be establishing mutual eye contact, knowing how to work together, being a team builder, communicating with others, and acknowledging and appreciating the knowledge of the other and not thinking that one has all the answers. I immediately saw that these were skills my students needed. Last year, at the MIDTESOL conference in 2016, I attended a workshop where the presenter talked about the need to teach her students how to disagree, how to interrupt a conversation, and how to hold the floor (Codney, 2016). Codney called these cultural norms. I see these cultural norms as falling under soft skills, which I interpret as part of cultural capital.

Another area that overlapped with what I was studying was metacognitive skills. According to Sun (2013), "[i]t is generally recognized that learners use meta-cognitive strategies to monitor, evaluate, regulate or manage his or her [sic] learning” (p. 2005). Metacognitive skills, then, refer to how to learn, how to go about performing tasks, and how to collaborate with partners in a meaningful way. These skills are important to teaching reading and writing, for example, where we often ask the students to proofread each other's papers. I soon realized a number of my students had no idea how to do this, so I had to teach them step-by-step. To teach these metacognitive skills, I used a video (tamuwritingcenter, 2010) that showed two girls proofreading each other's papers. This video is useful because it gives examples of what both effective and ineffective proofreading is. After discussing the examples and suggestions from the video, my students had a much better understanding of how to proofread their paper as well as how to work with a partner. I choose to think of this as a cultural difference and that in their past experiences they may have never learned how to do this kind of academic activity. Therefore, instead of thinking negatively, that my students didn't know how to proofread, I started to think that they simply had never been taught how to do so. This was a matter of cultural capital; proofreading was not part of their home country's education system or it was at least not explicitly taught. This new understanding started to change the way I approached my students. This, in turn, started to change the way I taught. I no longer thought of my students as being clueless, but instead started thinking that they just did not know a particular Western educational practice. I started to consider that that skill was just not part of my students' cultural capital. 


\section{Applying Cultural Capital in my Classroom}

\section{Displays of Affection}

In one class, I was having a specific behavior problem. My students were having a hard time concentrating on the lesson because they were very enamored by each other. They pretty much ignored my advice to "keep your hands to yourselves." This was not just a couple of students; several hands were around the backs of other students' chairs, hands on other students' seats, or even on another person's lap. Then I remembered that when my own sons were playing in their high school band, the teacher would say, "NO PDA," which stands for no public display of affection. So I searched the Internet and came up with several pictures. I showed them the pictures and said, "Students here in the USA know that public displays of affection are not permitted in schools." I did not elaborate; I just showed them the signs. To my surprise, that behavior stopped being a major problem. This did not happen overnight, but soon it was not an issue anymore.

Some cultural capital lessons, like this example, were short and to the point, thus I call them minilessons. If the lesson involved watching and discussing a video, it might take a few more minutes of class time. My goal was to develop a few lessons that could be used every semester, but as noted in the example above, the lessons may need to be specific for a particular group of students and to address a specific problem. So, this is an ongoing project.

\section{Learning Can Be Fun}

At some point during the semester, I showed my class a video (Edutopia, 2015) of American classrooms where students are free to sit and study in different spaces. I gave them a worksheet to follow and asked them to write a reaction. This was quite revealing. That semester I had students from several different nationalities. Some of my students felt that the students in the video were not serious about learning; they were just having fun. This was another revelation. Some of my students thought that having fun and learning did not go together, but the majority saw that learning was actually happening in this fun, collaborative environment. Here are some of their reactions:

\section{A student from China:}

"I think that schools should not limit the way that children study. I was always told you cannot, not and not."

Another student from China:

"If we talk, we will be punished like standing in the corner, or being cussed at by our teacher. We need to stare at the teacher and listen to what she says, receiving knowledge from the teacher."

A student from Japan:

"In my country all students just look at the teacher talking and taking notes. Nobody asks a question or discusses in class. However, in the US students talk to the teacher and other students they learn by themselves. This is so amazing!”

A student from the United Arab Emirates:

"If you learn to study with a group that makes me collect a lot of information from the group. So I like this because it encourages me to do a lot of activities without feeling bored."

These student comments revealed a difference between academic values in the US and their home countries. The students were beginning to add to their cultural capital by acknowledging or accepting the 
new educational behavior they were being exposed to. After we watched the video and talked about our reactions and the cultural differences, I said, "The students you will be in class with here at the university are like these students. They have worked with other students since kindergarten. This is the school experience that they are coming from.” At this point, I saw some jaws drop, their eyes opened wider, and I even heard little sighs as they realized that, yes, there is more to learning language than grammar, reading, and writing.

\section{Final Thoughts}

Cultural capital and associated concepts such as soft skills and metacognitive skills have informed the way I approach my students, and they have made me realize the need to be more explicit about teaching certain unspoken American classroom rules, attitudes, and behavior. In doing so, I have been able to address some behavior problems in my class, but more importantly, it has enriched my students' experience and hopefully better prepared them for their academic courses and for the global job market. As my colleague who introduced me to this topic of cultural capital said at that time, "Their parents did not send them to America just to learn English or accounting. They sent them to America to gain cultural capital.” 


\section{References}

Bourdieu, Pierre (1991) Language and Symbolic Power, trans. Gino Raymond and Matthew Adamson. Cambridge, MA: Harvard University Press.

Cimatti, B. (2016). Definition, development, assessment of soft skills and their role for the quality of organizations and enterprises. International Journal for Quality Research 10(1), pp. 97-130.

Codney, C. (2016) Understating and Responding to Assertive forms of Communication, MIDTESOL conference 2016, Emporia State University.

[Edutopia]. (2015, August 3). Flexible Classrooms: Providing the Learning Environment That Kids Need [Video File]. Retrieved from https://www.youtube.com/watch?v=4cscJcRKYxA.

Sun, Lihua. (2013). The effect of meta-cognitive learning strategies on English learning. Theory and Practice in language Studies (3), 11, pp. 2004-2009. doi:10.4304/tpls.3.11.2004-2009.

[tamuwritingcenter]. (2010, July 22). A Peer Response Demonstration [Video File]. Retrieved from https://www.youtube.com/watch?v=VCio7AbO3vo. 